are also concerned, the format of periodicals may likewise be involved, and it was observed in the debate that we may have to fix a date of five years hence rather than two for introducing the new standards. On March 30, Mr. Benn himself suggested that the function of the Post Office to-day could only be understood if it were regarded as a 'Ministry of Communications'. Nevertheless, the White Paper and Mr. Wedgwood Benn's own statements suggest that he needs to give much clearer and unprejudiced thought to the indirect as well as the direct effect of his proposals on the work of the Post Office alike as a social service and as a means of communication. However justified the new charges may be at the moment, it should be a primary objective of policy to reduce them at the earliest possible moment that the technical developments offer.

\title{
VACUUM BREAKDOWN
}

D URING April 12-13 a working party met at the University College of Swansea to discuss research now being undertaken on the basic processes underlying the phenomenon of the breakdown of vacuum insulation. This working party was organized jointly by Mr. W. F. Gunn, of the Atomic Weapons Research Establishment, and Dr. J. Dutton, of the Department of Physics, University College of Swansea. The invited participants numbered about twenty and comprised those actively undertaking or closely concerned with research in this subject, and included scientists from France, Switzerland, the United States, and Britain. The procedure differed from that usually followed in conferences in that there were four sessions, each containing one short paper only, the function of which was to stimulate discussions on particular facets. This procedure proved to be entirely satisfactory in that discussion was free, vigorous and extremely helpful.

After welcoming the working party, Prof. Llewellyn Jones (University College of Swansea) outlined the general phenomena of vacuum breakdown and surveyed the present theories of the processes and lines of investigation. The first session was devoted to breakdown processes in small gaps at ambient pressures of $10^{-5}$ torr, and a paper by Dr. W. D. Owen (Atomic Weapons Research Establishment) showed how breakdown would follow from the release of adsorbed gas molecules from electrode surfaces under electron bombardment by pre-breakdown field-induced currents. The ensuing discussion dealt with the dependence of the processes on the surface state, and this led to quantitative estimates of the size $\left(\sim 10^{-11} \mathrm{~cm}^{2}\right)$ of electron emitting areas.

The next session was devoted to a detailed study of the initiation, growth and destruction of microscopic metal protuberances. A detailed mathematical analysis of the stability of a local disturbance on a plane surface in an electric field was given by Dr. F. Rohrbach (CERN). This showed how the growth and stability of a protuberance were dependent on surface tension and other physical properties of the metal. This paper led to exciting discussions on the feasibility of ever obtaining perfectly plane surfaces in electric fields, and the implications of this in various electronic applications were discussed. It was shown from the theory that a particularly effective surface for minimizing cold emission could be obtained by a prepared surface of aluminium oxide with micro- scopic protuberances of almost $\Omega$-shaped section. Electrodes with this type of surface had been found in practice to be able to withstand high electric fields in vacuum in large gaps.

In the third session, Mr. A. Maitland (University of St. Andrews) gave a survey of some of the problems associated with electron beams and their role in vacuum breakdown. In the following discussion, attention centred on the form and stability of observed discharges. The final session was devoted to breakdown in high vacuum ( $\leqslant 10^{-9}$ torr). Mr. J. Beynon (University College of Swansea) described work directed to the evaluation of the effect of adsorbed gas molecules in ultra-high vacuum breakdown. Ho showed how their removal from the electrode surfaces by heat-treatment reduced the incidence of the usual prebreakdown current pulses and associated release of gas, and thus led to almost stable conditions. These observations were consistent with the view that pre-breakdown (Fowler-Nordheim) cold emission from emitting sites of very small area $\left(\sim 10^{-10}-10^{-11} \mathrm{~cm}^{2}\right)$, which could well be microscopic protuberances discussed earlier, could release minute quantities of adsorbed gas which was detected by ionization gauges.

In summing up the meeting, Prof. Llewellyn Jones attempted to draw an overall and consistent picture of the succession of processes constituting $a$ mechanism of vacuum breakdown. This involved a full discussion of the nature and stability of surfaces in general, and it was agreed that the development of surface protuberances in electric fields could well provide the emitting areas which would be consistent with the areas deduced from the observed pre-breakdown field emission currents. These currents could then set in train other processes such as desorption of gas molecules from electrode surfaces to make possible gas ionization and current amplification. The general opinion was that the ambient atmosphere necessary to produce this amplification in the experiments discussed seemed more likely to be due to desorbed gas rather than to metal vapour from the explosion of protuberances caused by high-current density field emission.

The meeting, which was greatly appreciated by those present, ended with accounts of the future research programmes which the various laboratories proposed following as well as of those lines of approach which appeared most promising.

\section{EXPERIMENTAL TAXONOMY OF FLOWERING PLANTS}

A SYMPOSIUM on "The Experimental Taxonomy of Flowering Plants" was held at the Linnean Society on March 5. Prof. D. H. Valentine introduced the symposium and took the chair at the morning session; Dr. P. R. Bell, vice-president of the Society, took the chair in the afternoon.

The first paper, on "Fruit Variation in the Carex glareosa Complex", was by Dr. G. Halliday and Mr. A. O. Chater, of the University of Leicester. They described in detail the disjunct circumpolar distribution of this group of sedges, and pointed out that its components, C. glareosa Wahlenb. and C. marina Dewey, are commonly regarded as being specifically distinct. The main dis. tinguishing character is in the shape of the fruit, the former species having fusiform fruits, and the latter shorter, broader and more or less beaked fruits, but intermediate types occur. Careful examination of an extensive range of herbarium material, some of it collected 
by the authors, has shown that the extremes are indeed connected by a continuous series of intermediates, but that the marina form is the most frequent and widespread, though the glareosa form is the most frequent in Scandinavia. In several places, there is strong evidence that the population is polymorphic, with both forms growing together. No cultivation experiments have been performed, but it seems very unlikely that the differences are due either to phenotypic plasticity or to differences in the time of the maturation of the fruits. Self-pollination is possible in the group, though there is no proof of selfcompatibility. It is thought most likely that the present situation is the result of the mingling of two previously allopatric populations, which are occasionally hybridizing, though at present this is no more than a plausible hypothesis.

The second paper, on "The Genus Dryas in Greenland", by Dr. T. T. Elkington, of the University of Sheffield, led on very naturally from the first. Eurasian and North American Dryas consists of a very small number of species, and in the Atlantic region there are probably only two-D. octopetala L. of Europe and D. integrifolia Vahl. of North America. These species have both been reported from Greenland, together with intermediates, which have been described as D. chamissonis. The Dryas populations of Greenland were accordingly investigated, both from the very extensive herbarium collections at the University of Copenhagen and in the field. The herbarium material was scored for a series of leaf characters which included shape, crenation and hairiness. When this information was plotted on a map of Greenland, it revealed $D$. integrifolia in the west, integrifolia with occasional octopetala and hybrids in the north, and octopetala with occasional integrifolia and some hybrids in the east. Field studies (in the eastern region, latitude $72^{\circ} \mathrm{N}$ ) were made over an area about thirty miles across in which some twenty well-spaced localities were sampled, some of them by transects. In nearly all the populations, extensive character variation could be observed, and this variation was not correlated with type of community or of soil. So far as can be observed, both species occupy exactly the same kind of habitat, and the distribution of the members of the hybrid swarm is apparently more or less random. Floral differences are slight and were not scored. Both species are diploid; meiosis in field samples of hybrids was regular and there was an abundant set of seed. Artificial hybrids have been made but have not yet reached maturity. Taxonomically, $D$. integrifolia and $D$. octopetala are best maintained as species; biosystematically, they can be regarded as incipient ecospecies. In the discussion, reference was made to the polymorphy of some British Dryas populations with respect to hairiness, and the possibility was raised that this might be ascribable to remote hybrid origin (D. integri. folia lacks leaf hairs, $D$. octopetala generally has them).

The third paper, by Mr. J. E. Cousens, of the Forestry Department, University of Edinburgh, was on "Sources of Variability in the Native Oaks". Mr. Cousens began by describing his work on the Scottish oaks. Using selected diagnostic characters and standardized sampling methods, he constructed pictorialized scatter diagrams for a large number of populations, and was able to show that the pattern of variation corresponded to what would be expected if there were two taxa and widespread introgression, though neither $Q$. petraea nor $Q$. robur could be confidently defined. Extension of the survey to Ireland showed that most populations of oaks corresponded closely to $Q$. petraea (Matt.) Liebl. and that hybrid populations were not frequent. In England, Q. robur $\mathrm{L}$. populations which showed no signs of introgression were hard to find, and an investigation was accordingly made of oaks in the flood-plain of the Danube in north Yugoslavia in an attempt to find an area in which $Q$. robur was not in contact with $Q$. petraea, so that parameters for non-introgressed populations could be obtained. In fact, the heterogeneity in the Yugoslav populations was just as great as in England, possibly because of contacts between $Q$. robur and other species such as $Q$. frainetto. It is probable that in British populations $Q$. robur is inherently variable, and that in England it hybridizes relatively rarely with $Q$. petraea, but in Scotland hybridization, possibly because of a greater overlap in flowering times between the two species, is more widespread. In the discussion, the difficulty which sometimes arises of distinguishing between variation attributable to introgression and to other causes was pointed out. The problem of distinguishing between native and introduced oaks was also referred to.

The next paper was given by Mr. P. L. Pearson, of the University of Durham, on "The Experimental Taxonomy of Chrysanthemum leucanthemum L.". This aggregate species has a wide distribution in Europe, and has been extensively studied by taxonomists and cytol. ogists. On the basis of some three hundred known chromosome counts, it can be inferred that the northern lowland populations generally consist of a mixture of diploid and tetraploid populations, while in the Pyrenees and the Alps hexaploids also occur. In Britain, diploids are predominant in the more natural habitats, such as sea cliffs and mountain ledges, while tetraploids are commonest in disturbed habitats. Artificial autotetraploids produced by colchicine treatment resemble natural tetraploids closely in their cytological behaviour, both forming one or two quadrivalents at meiosis, and only very rarely univalents and trivalents. This pairing behaviour is characteristic of many wild and artificial tetraploids, and models to explain it were discussed. Triploids have also been obtained, in low yield, in artificial crosses but have not been found in the wild. There are no clear-cut morphological differences between British diploids and tetraploids, though by using a combination of leaf and pollen-grain characters, some plants can be correctly placed; the correct taxonomic treatment must await further investigation. In the discussion, Dr. K. Jones raised the question of the possible hybrid origin of the wild tetraploids, and suggested further investigations on chromosome morphology.

The next paper, by Mr. Q. O. N. Kay (University College of Swansea), was on "Chromosome Numbers, Breeding System and Relationships of Tripleurospermum inodorum (L.) Schultz Bip. and T. maritimum (L.) Koch". The scentless mayweed ( $T$. inodorum) is a common cornfield annual; in the British Isles and north-west Europe it is diploid, with $2 n=18$, while in central and eastern Europe it is tetraploid. The tetraploid form has been found rarely as a casual in England; it differs slightly in physiology and morphology from the diploid, and partially fertile triploid hybrids have been produced. Investigations on the variation in British populations reveal a cline of increasing achene size from southern England to the north of Scotland. The closely allied species $T$. maritimum is a perennial sea-cliff and drift-line plant and is uniformly diploid. Generally it is efficiently isolated from $T$. inodorum, but occasional hybrid populations have been found; artificial hybrids are fertile. One or two $B$-chromosomes have been found in some diploid plants of both species. It is remarkable that not only the perennial $T$. maritimum but also the annual $T$. inodorum are normally self-sterile (though occasional self-fertile plants of the latter occur). The suggestion was made (and discussed) that the current generalization about a correlation between the annual habit and inbreeding is illusory, as there are, in fact, many annuals which, like $T$. inodorum, are normally out-breeding.

The last paper, on "Experimental Taxonomic Studies on Caltha palustris L.", was given by Mr. M. KootinSanwu, of the University of Oxford. $C$. palustris is represented in Britain by three sub-species, subspp. palustris, radicans and minor; cultivation experiments have substantiated the differential characters (which 
include size and ability to root at the nodes) between these sub-spocios. The only chromosome numbers regularly found are $2 n=56$ and $2 n=64$, though some populations have, in addition, $B$-chromosomes. In Continental Europe, a diploid with $2 n=14$ is known from one locality, and tetraploids $(2 n=28$ and $2 n=32)$ also occur. Thero are thus, apparently, two basic numbers to the polyploid sories. The tetraploids examined always show bivalent pairing, but the octoploids have some quadrivalents as woll as univalents. In the extensive collections studied, all the plants were self-incompatible and hence outbreeding, and the wild populations were all somewhat polymorphic. There appeared to be little morphological difference between members of the same sub-species with different chromosome numbers. Plants at the same chromosome-level were all interfertile, but there was some drop in fertility in crosses betweon plants with 56 and 64 chromosomes. Information was also presented about tho frequency of $B$-ehromosomes in natural populations and their mode of inheritance.

In the general discussion opened by Prof. Valentine, the phytogeographical questions raised by some of the papers were pointed out. Thus, the distributions of the Dryas spp., the Quercus spp., and the Chrysanthemum and Tripleurospermum cytodemes, all posed probloms about the conditions in the past under which speciation had occurred, and the subsequent conditions in which allopatric populations had become sympatric to varying extents. Dr. D. M. Moore mentioned the South American species of Caltha which, unlike $C$. palustris, were selfcompatible, and suggested that this might be an examplo of Baker's law concerning the breeding system of successful long-distance migrants.
D. H. VALENTINE

\section{ROCK AND MINERAL COLLECTING IN CANADA}

$I^{\mathrm{T}}$ $\mathbf{T}$ is surely an innovation, a most welcome one, to find an official Geological Survey publication devoted entirely to the needs of the enthusiastic amateur or professional geologist bent on collection of fine mineral and type-rock specimens. But this has in fact been surprisingly and most efficiently achieved in three small com. panion volumes by Ann P. Sabina recently published by the Geological Survey of Canada*. These make most instructive and, if not to other countries, provocative reading - provocative in the sense that one could wish that the example could be emulated elsewhere on the same scale. To traverse the length and breadth of this farflung Dominion with the sole object of guiding people exactly where and how to travel to discover the best specimens of minerals, in many cases obviously museum pieces, also of well-known or more exotic rock-types; to give them maps, precise site-locations, itineraries, descriptions of the 'finds' to be obtained; information on where to look for the best material, how to collect, the working tools to use, even appropriate clothing to wear, also how to preserve and record what has been collected: all this within three small pocket-size booklots, easily readable by virtue of the non-technical style adopted, is a great achievement indeod.

The plan of each of these guides is straightforward and orderly. Volume 1 covers Yukon, North-west Territories, and the Provinces of British Columbia, Alberta, Saskatchewan and Manitoba. Volume 2 is concerned with Ontario and Quebec (this is the largest of the three). Volume 3 covers New Brunswick, Nova Scotia, Prince Edward Jsland and Newfoundland. The common scheme in every case is to list the chief mineral and rock collecting areas in each Province, include a small-scale map showing the locations of these areas, and follow by a detailed description of each area headed by the mineral or rock titles to be anticipated in each area. In many cases small location maps, but on a sufficiontly large scale, are inset for these areas so that no difficulty can possibly arise from inability to locate the site. Each book is enriched with some beautiful photographic reproductions of museum type specimens collected from localities described in the text.

These records of Canadian mineral occurrences are not, only impressive but also must inevitably whet the inborm collector's appetite wherever he may be. The search is, as customarily everywhere, in mines (tip-heaps never to be neglected however ancient), natural outcrops (including alluvial gravels and beach deposits in specific areas) and

* Rock and Mineral Collecting in Cunada. By Ann P. Sabina. Vol. 1 Yukon, Northwest Territories, British Columbia, Alberta Saskatchewan and Manitoba; pp. iv $+147 ; 1.30$ dollars. Vol. 2 . Ontario and Quebec; pp. iv + $252 ; 1.65$ dollars. Vol. 3. New Brunswick, Noma Scotia, Prince Edward Island, Miscellancous Report 8, Ottawa; 1964). quarries. Some tempting records of fine mineral specimens taken at random from these pages may be quoted: in Yukon Territory (Kluane Lake-Whitehorse Area), black olivine crystals often more than $3 \mathrm{in}$. in length; in Northwest Territories (Macbeth Fiord Area, Baffin Island), tourmaline crystals up to $3 \mathrm{ft}$. long and 6 in. across in pegmatite dykes; in Amadjuak Bay-Lake Harbour Area, Baffin Island, white scapolite crystals 5 in. in diameter in crystalline limestone; in Great Slave Lake Area, blue cordierite prismatic crystals up to 4 in. $\times 2$ in.; in British Columbia (Hazelton Area), scheelite crystals up to 2 in. in diameter; in Vernon Area, thick crystals of staurolite up to $3 \mathrm{in}$. long and associated kyanite crystals more than 2 in. long; in Saskatchewan (Mackintosh Bay), red garnets up to $2 \mathrm{in}$. across in biotite schist, and in the Cypress Hills Area, selenite crystals up to 5 in. long; in Manitoba (Winnipeg River Area), green beryl crystals from 0.5 in. to 12 in. across. In Ontario (Sudbury Area), blue and green bladed kyanite up to 4 in. long; in Wilberforce Area, hornblende and apatite crystals up to 6 in. across, also uraninite in 0.75 in. crystals; in Baneroft Area, black mica in 'books' up to $2 \mathrm{ft}$. in diameter; in Quebec (PreissacLacorne Area), spodumene crystals up to $4 \mathrm{ft}$. long; similar impressive mineral finds are chronicled from New Brunswick, Nova Scotia, Prince Edward Island and Newfoundland. Descriptions of localities of many wellknown igneous rock-types of special interest to the petrologist are to be found throughout these books.

Some other interesting features are to be noted from these guides. The Geological Survey of Canada makes available to mineralogists, students and others authenticated sets of specimens to aid identification and recognition of rocks and minerals; one set comprises 35 common mincrals, another 35 rock chips, and a third, 120 specimens representing the raw materials of Canada's mineral industry. The names and addresses of amateur mineral and rock clubs, of which no less than fifty-five are spread over the Dominion, are listed; appendixes include lists of books on mineralogy in general, on minerals and rocks for the amateur, on gemmology, and on the lapidary's art.

There is room for a similar official publication in the United Kingdom. It would in no sense transgress the existing periodic geological and mineralogical publications of national and local societies, or of the Geological Survey as such, wherein much comparable information at present lies buried. Its advent would do much to stimulate public interest in geology and mineralogy, and would certainly be a boon to schoolteachers in their task of presenting these subjects to beginners both in the classroom and in the field. A similar idea for guidance in fossil collecting is by no means excluded from such consideration, surely an equally popular hobby with many amateur geologists? 